\title{
Effect of Ambient Air Temperature on the Performance of Petrol Engine
}

\author{
Dr. Ramzi R. Ibraheem ${ }^{1}$, Kawa A. Abdullah ${ }^{2}$ \\ ${ }^{1}$ Assistant professor, ${ }^{2}$ Lecturer \\ Department of Mechanical Engineering, College of Engineering, University of Salahaddin. \\ ramzi.Ibraheem@su.edu.krd,kawa.abdullah@su.edu.krd
}

\begin{abstract}
The purpose of the present study is to investigate the effect of ambient air temperature on the performance of spark ignition engine, and exhaust gas temperature. Various factors taken that affects the performance of four- stroke petrol engine. An experimental study is carried out to investigate engine performance parameters. The experimental results demonstrate that the method proposed to measure the intake ambient air temperature at different engine speeds. The different ambient air temperature was taken $(10,20,30,40$ and $50^{\circ} \mathrm{C}$ ) at different climate conditions and in the different engine speeds (1500, 2000 and 2500 r.pm). The results of experimental shows that increasing ambient air temperature will improve the fuel consumption and thermal efficiency about (14\%- 16\%) consecutively. It is also shows decrease in the volumetric efficiency with increasing ambient air temperature. However, by increasing sucked air temperature, will lead to increase exhaust gas temperature.
\end{abstract}

Keywords: Ambient air temperature, Spark ignition engine, Thermal efficiency, Volumetric efficiency and Exhaust gas temperature.

\section{Paper History:}

(Received: 17/10/2016; Accepted: 09/10/2017)

\section{Introduction}

The internal combustion engine is a system that converts heat or thermal energyand chemical energyto mechanical energy, which can then be used to do mechanical work. Numerous factors effects on engine performance and ability to burn mixtures like ambient air temperature. (Watanabe et al., 1981) studied the effect of inlet air temperature on the power output from a twostroke crankcase compression gasoline engine. Their effort was focused on determining a correlation for the power output of the engine as a function of the absolute inlet temperature in a range of $4.5^{\circ} \mathrm{C}$ to $40{ }^{\circ} \mathrm{C}$. The authors derived a relationship between the power output and the scavenging pressure to show that as the temperature decreases the power will decrease due to a decrease in scavenging pressure with increasing ambient temperature. Temperature has also been shown to have a large impact on the formation of several important combustion products or emissions. Combustion products such as Nitric Oxides, NOX, unburned hydrocarbons, UBHC, and Carbon Oxides, $\mathrm{CO} 2$ and $\mathrm{CO}$, are all important in relation to combustion efficiency and the ever increasing pressure to reduce greenhouse gases produced by internal combustion engines. (Flynn et al., 2000 ) showed that there is an approximate minimum temperature under which conditions are such that a chemical combustion reaction will not occur thus NOX will not be produced. They also showed the impact of temperature on the productionof UBHCs, where reduced combustion temperatures will increase the amount of UBHC in the emissions. (Wilson,C., 2010) ran several experiments in an effort to determine the effects of fuel heating and ultimately mixture temperature on the torque and BSFC of a small internal combustion engine.

The tests utilized a Fuji B-34 single cylinder four stroke spark ignition engine with stock timing as the test engine. The conclusion from these tests presented by Wilson is that heating the fuel alone has little impact on the overall engine performance. Wilson also concluded that the impact of equivalence ratio on engine performance is significant and can be greatly impacted by carburetor setting and fuel temperature. ( Laurinaitis et al., 2013) the analysis of the combustion characteristics of homogeneous charge compression ignition (HCCI) combustion using diesel fuel, jet fuel, gasoline and ethanol. The experiments were conducted on a modified four-stroke, fourcylinder engine at constant engine speed of 1400 $\mathrm{rpm}$. The effect of the intake air temperature, relative air/fuel ratio and exhaust gas recirculation (EGR) rate on the combustion parameters and emission were analyzed. The experimental results indicate that the intake-air temperature, air fuel ratio and EGR rate have significant effect on the maximum in-cylinder pressure, heat release rate, start of combustion and emissions.

The aim of this study is to test the influence of increasing ambient air temperature on performance parameters of the petrol engine. 


\section{Performance parameters}

To determine engine Brake power, Brake mean effective pressure, and volumetric efficiency, brake specific fuel consumption, thermal efficiency must apply the following equations: (Haywood et al., 1988) [2]

\subsection{Engine power}

Power is the amount of work done per unit time or the rate of doing work.

B. $P=\frac{2 \pi N T}{60 \times 1000}$

\subsection{Brake mean effective pressure}

For any particular engine, operating at a given speed and power output, there is brake mean effective pressure (B.m.e.p) derived from brake power: (Cussons Technology., 2004)

$$
\text { B. m.e.p }=\frac{60 \times 1000 \times B . p}{L \times A p \times n \times K}
$$

\section{2 .3 Fuel-air ratio:}

It is the ratio of the mass of fuel to the mass of air in the fuel-air mixture

$$
A /_{F}=\frac{m a}{m f}
$$

\subsection{Specific fuel consumption}

It is a measure of the fuel efficiency of eninge that burns fuel and produces rotational, or shaft, power

$$
S . f . c=\frac{m f}{B . p}
$$

\subsection{Volumetric efficiency}

It is defined as the ratio of actual volume of the charge drawn in during the suction stroke to the swept volume of the piston

$$
\eta_{\mathrm{v}=} \frac{\text { Air consumption of stroke }}{\text { piston displacement }}
$$

\subsection{Thermal efficiency}

It is the efficiency of a heat engine measured by the ratio of the work done by it to the heat supplied to it.

$$
\eta_{\mathrm{th}}=\frac{B . p}{m f \times C . V}
$$

\section{Results and Discussions:}

Experiments were performed to study the effect of ambient air temperature on the engine performance parameters and exhaust gas temperature. Each test cycle was conducted at different ambient air temperatures (10, 20,30, 40 $\& 50{ }^{\circ} \mathrm{C}$ ) due to simplicity in getting data at the different climate conditions at constant throttle opening. The results of the measured and calculated data in the experiments are displayed in the following Figures:

Figure 2 illustrates the effect of ambient air temperature on brake power at different engine speeds $(1500,2000 \& 2500$ r.p.m). It was observed that the brake power decreased with increasing inlet air temperature. Because by raising intake charge temperature, the charge density is reduced and the engine receive less air flow rate. Figure 3 shows the volumetric efficiency as a function of intake air temperature. It is clear that the volumetric efficiency decreases with increasing the temperature of sucked air because the density of the intake air is decreased and consequently the quantity of air that is trapped by the cylinder during induction is reduced compared to the constant swept volume of the cylinder. Figure 4 shows the effect of inlet air temperature on specific fuel consumption. The specific fuel consumption increases with increasing inlet air temperature because higher ambient air temperature enhances the conversion of chemical energy into heat energy and make the air fuel mixture to promote better combustion. Figure 5 shows the thermal efficiency as a function of ambient air temperature. Experimental results showed that, ambient air temperature has a little effect on brake thermal efficiency. A decrease in ambient air temperature improved brake thermal efficiency. Figure 6 shows the exhaust gas temperature variations with ambient air temperature at constant throttle opening and at different engine speeds (1500, 2000 and 2500 rpm). In this figure the exhaust gas temperature value is increased with increasing the ambient air temperature. In general increasing charge air temperature leads to increase in combustion temperatures and consequently increases exhaust gas temperature. 
Table 1 Engine technical data sheet. (Cussons Technology., 2004).

\begin{tabular}{|c|c|}
\hline Item & Description \\
\hline Number of cylinders & 4 in line \\
\hline Bore & $62.52 \mathrm{~mm}$ \\
\hline Stroke & $69.09 \mathrm{~mm}$ \\
\hline Swept volume & $848 \mathrm{~cm}^{3}$ \\
\hline Compression ratio & $9.5: 1$ \\
\hline Ignition sequence & 1342 \\
\hline Maximum power & $30 \mathrm{kw}$ at $5500 \mathrm{r} . \mathrm{p} . \mathrm{m}$ \\
\hline Maximum torque & $63 \mathrm{Nm}$ at $3500 \mathrm{r} . \mathrm{m} . \mathrm{m}$ \\
\hline Ideal speed & $900 \mathrm{r} . \mathrm{p} . \mathrm{m}$ \\
\hline Inlet valve 5 clearance & $0.15 \mathrm{~mm}$ \\
\hline Exhaust valve 5 clearance & $0.15 \mathrm{~mm}$ \\
\hline Spark plug gap & $0.64 \mathrm{~mm}$ \\
\hline Contact breaker gap & $0.38 \mathrm{~mm}$ \\
\hline Crank radius & $34.54 \mathrm{~mm}$ \\
\hline
\end{tabular}

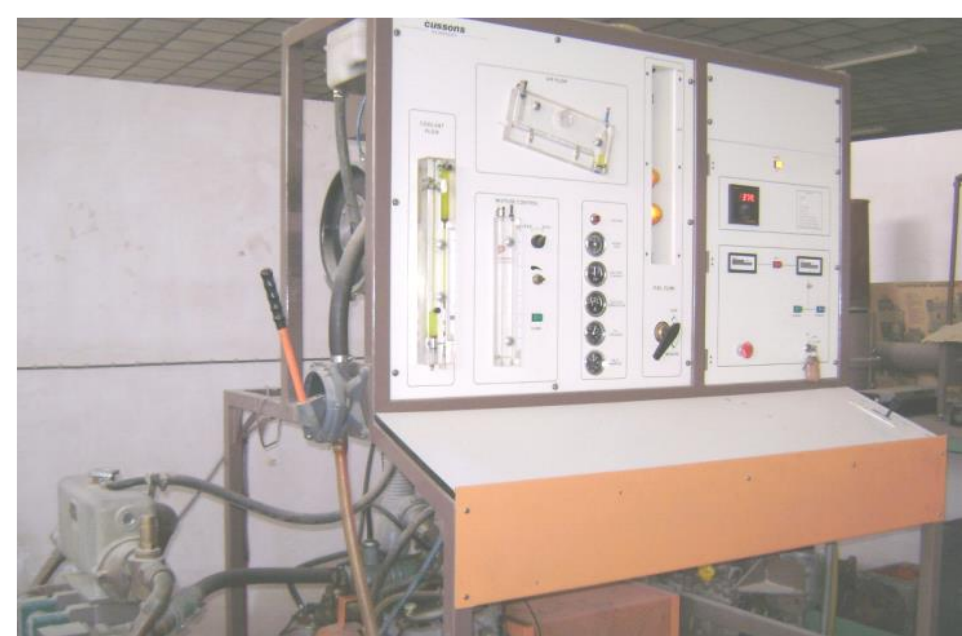

Figure 1: View of the reliant engine test rig by Cussons Technology., 2004 [1]

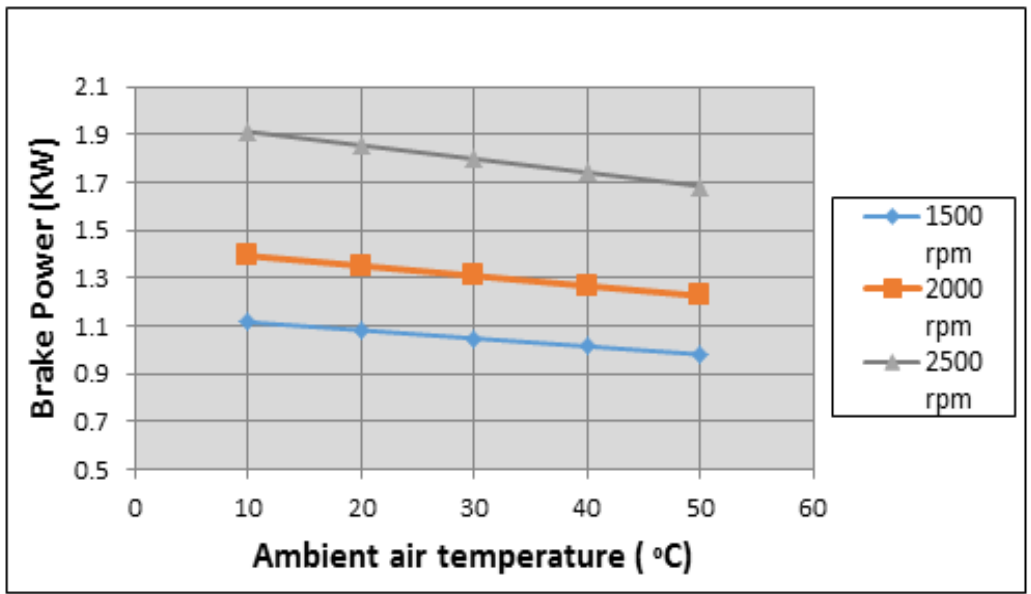

Figure (2): Effect of inlet air temperature on the brake power, at different engine speeds 


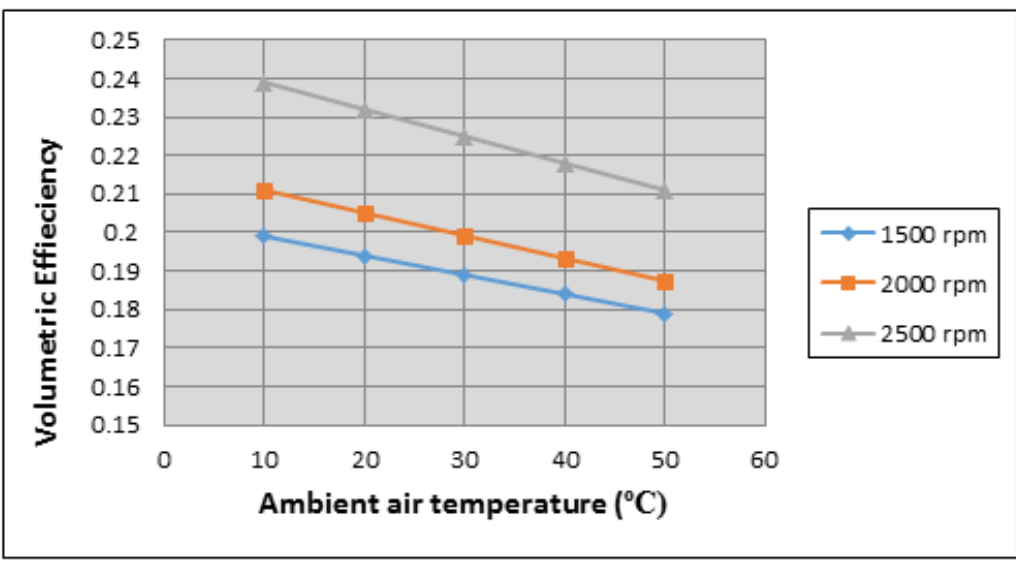

Figure (3): Effect of inlet air temperature on the volumetric efficiency, at different engine speeds

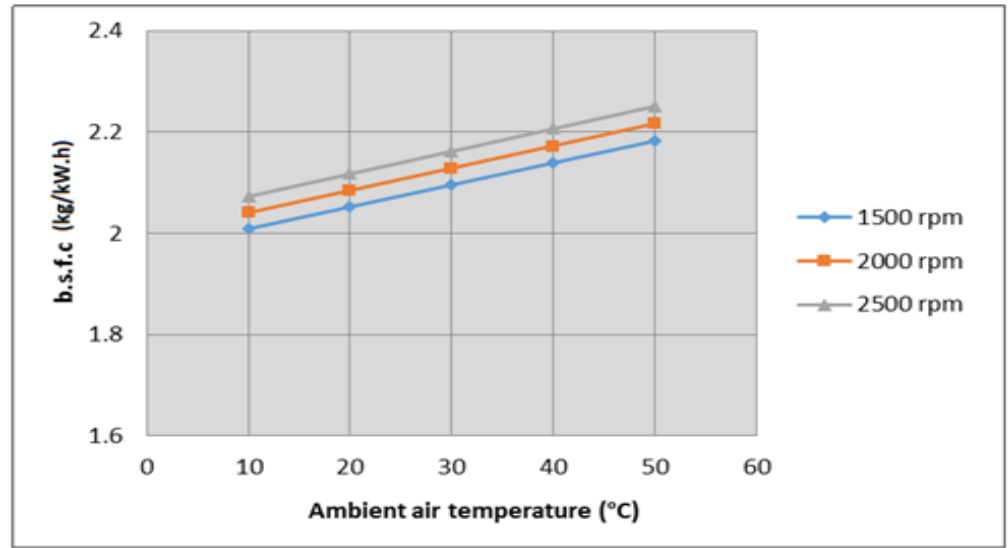

Figure (4): Effect of inlet air temperature on the brake specific fuel consumption, at different engine

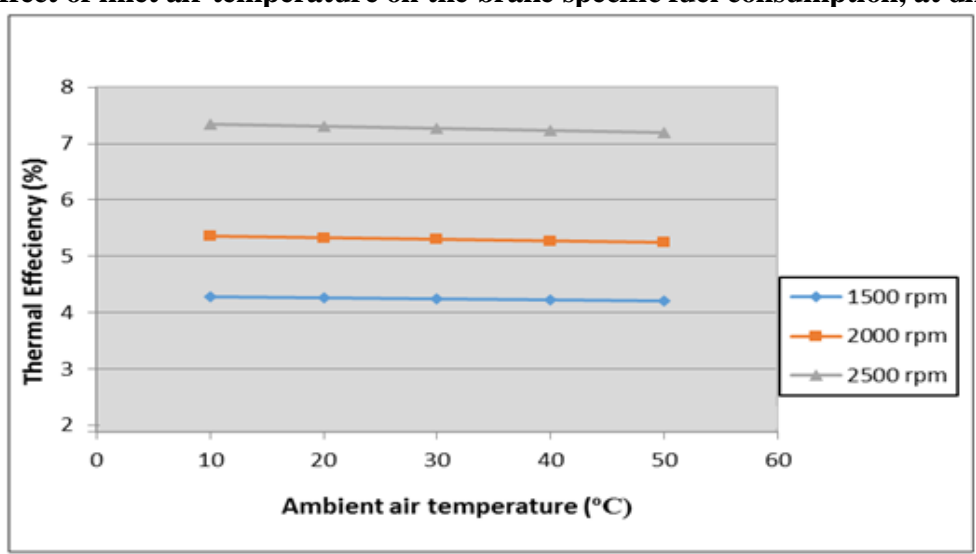

Figure (5): Effect of inlet air temperature on the brake thermal efficiency, at different engine speeds

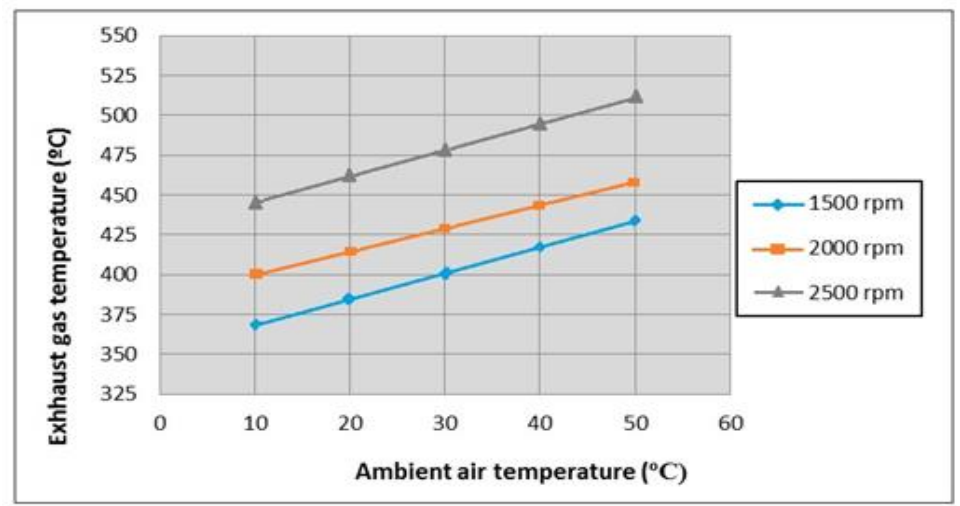

Figure (6): Effect of inlet air temperature on the exhaust gas temperature, at different engine speeds 


\section{Conclusions}

This research examined the effect of intake ambient temperature on exhaust gas temperature, brake power, brake mean effective pressure, thermal efficiency and volumetric efficiency in spark ignition engines. The results have indicated that the effect of intake ambient temperature is remarkably significant. The results described above gave justification to some conclusions:-

1. Cooler intake air will be denser and have higher mass flow per piston-cycle. Getting more mass of oxygen into the cylinder will allow more fuel to be burnt, making each cycle produce more brake power.

2. Increasing inlet mixture temperature from (20-50) ${ }^{\circ} \mathrm{C}$ improve in fuel consumption and thermal efficiency about $(16 \%, 14 \%)$ consecutively

3. Generally, increasing the intake air temperature leads to decrease in volumetric efficiency due to decrease the density of intake air, as a result less air volume draws into the cylinder to the cylinder's swept volume.

4. Generally, the increase of ambient temperature has a low significant effect in thermal efficiency.

5. The increase in intake ambient temperature directly raises combustion temperature and exhaust gas temperature.

6. To decrease the effect of high ambient air, some engines will cooperate intercooler to improve their volumetric efficiency by increasing intake air charge density through nearly isobaric (constant pressure) cooling.

\section{Refferences}

[1]. Cussons Technology., P8160 Single Cylinder Engine Test Bed, User's Manual 2004.

[2]. Haywood, John B., Internal Combustion Engine Fundamentals; McGraw-Hill, Inc., 1988.

[3]. Flynn, P.F., Hunter, G.L., The Inevitability of Engine-Out NOx Emissions from SparkIgnition and Diesel Engines, 28th International Symposium on Combustion, Edinburgh, Scotland, 2000.

[4]. Kett, P. W., Motor Vehicle Science, Part 2, Chapman and Hall in Association with Methuen, 1982.

[5]. Laurinaitis, Kastytis; Slavinskas, Stasys., Influence of Fuel Type and Intake Air Properties on Combustion Characteristics of
HCCI Engine), Engineering for Rural Development - International Scientific Con; 2013, p308.

[6]. Watanabe, I., Kuroda, H., Effect of Atmospheric Temperature on the Power Output of a Two-Stroke Cycle Crankcase Compression Gasoline Engine, 810295, SAE International Congress and Exposition, Detroit, MI, 23-27 February 1981.

[7]. Wilson, C., Performance of a Small Internal Combustion Engine Using NHeptane and Iso-Octane), AFIT Thesis, AFIT/GAE/ENY/10-M28, Air Force Institute of Technology, Wright Patterson AFB, OH, 2010.

[8]. Willard .W. Pulkrabek, Engineering Fundamentals of The Internal Combustion, Prentice-Hall-Inc, 1997.

[9]. Y. A. Cengel and M. A. Boles, Thermodynamics: An engineering approach, McGraw-Hill Higher Education, 2006. 